the same activity, but one month earlier at Arc-en-Barrois. Most females exhibited a sexual rest characterized by a regression of genitals and an anoestrus, late summer - early autumn. The breeding season could be more than one month earlier when the oak mast crop was abundant, especially at Chambord (1975-1976 and 1976-1977). As their body development was rather slow, these wild sows living in the forests were pregnant for the first time at the mean age of 18-24 months and at a live weight exceeding $25 \mathrm{~kg}$.

The potential prolificacy estimated from the number of embryos, was low ( $n=4.41$ at Chambord; $n=4.75$ at Arc-en-Barrois). Like in the sow, it varied with the age and weight of the animal. Maximum litter size was reached between 4 and 5 years of age and 2 animals out of 179 carrying 9 foetuses weighed more than $100 \mathrm{~kg}$. The ovulation rate was not very high either (5.05 and 5.5, respectively at Chambord and Arc-en-Barrois and the average embryonic mortality was 13.4 p. 100 . However, this rate varied between a minimum of 12 p. 100 when fall food was abundant and up to 19 p. 100 in years of food scarcity.

Weighing of the ovaries (and of the empty uterus) gives information about the physiological status of the wild sow and allows to clearly distinguish between the infantile phases ( 2 ovaries weighing less than $2 \mathrm{~g}$ ), sexual rest phase (less than $3 \mathrm{~g}$ ), and the cycle followed by gestation $(6-7 \mathrm{~g})$. Weighing of the foetuses allows to describe the mean weight gain in the young $(y)$ by a parabolic equation according to gestation length $(x) Y=236.6-13.02 x$ $+0.176 \mathrm{x}^{2}\left(\mathrm{R}^{\prime \prime}=0.97\right)$. The chemical body analysis of the embryos indicates a dry matter increase with age, a large proportion of proteins and a very low lipid content, as shown in piglet embryos.

The consequences of biological and physiological knowledge about the wild sow, are discussed.

III. - GENETICS

\title{
First results of experiments with chinese pigs in France 1. Reproductive performance in pure and cross breeding with european breeds
}

\author{
C. LEGAULT *, J.C. CARITEZ * \\ I.N.R.A., Station de Génétique quantitative et appliquée, \\ F 78350 Jouy-en-Josas \\ ** I.N.R.A., Domaire expérimental du Magneraud, \\ Saint-Pierre-d'Amilly, F 17700 Surgères
}

The reproductive performance of three native Chinese breeds : Meishan (MS), Jiaxing (JX) and Jinhua $(\mathrm{JH})$ were compared with those of six genetic types of F1 females resulting from the cross of one boar of each Chinese breed with twelve sows of two European breeds : Large White (LW) and French Landrace (LF).

Estimated on a total of 278 purebred and 226 crossbred animals, the average teat number was $16.3 \pm 1.1$ in MS; $19.9 \pm 1.4$ in $\mathrm{JX} ; 16.5 \pm 1.1$ in $\mathrm{JH} ; 14.7 \pm 1.6$ in $\mathrm{F} 1 \mathrm{MS}$; $16.7 \pm 1.7$ in $\mathrm{F} 1 \mathrm{JX}$; and $15.8 \pm 1.4$ in $\mathrm{F} 1 \mathrm{JH}$. On a total of 75 purebred and 114 crossbred gilts, age at puberty was $81 \pm 9 ; 91 \pm 10 ; 109 \pm 15 ; 87 \pm 11 ; 93 \pm 13$ and $96 \pm 14$ days, respectively, for these six genetic types.

Litter size, litter weight and food intake of the sow during the suckling period ( 30 days), were measured on 178 farrowings of which 105 were from gilts.

As far as prolificacy is concerned, we may distinguish between two groups whose litter size at birth and weaning were significantly different. The «prolific» group included four F1 types (MS $\times \mathbf{L F}, \mathbf{M S} \times \mathbf{L W}, \mathrm{JX} \times \mathbf{L F}$ and $\mathrm{JX} \times \mathbf{L W}$ ) and one purebreed (MS). Mean litter size at birth varied from 13.4 to 14.7 and at weaning from 11.4 to 13.3. 
Litter weight at 21 days and milk production of the sow permit to distinguish between three different groups : the best performance was observed in seven genetic types (the five «prolific» types and the two European breeds, LW and LF). The poorest results were obtained in two purebreeds ( $\mathbf{J X}$ and $\mathbf{J H}$ ), with half bred $\mathrm{JH}$ occupying an intermediate position.

On the basis of the intake of concentrate feed during lactation, we may distinguish between three groups whose means were significantly different : European sows (LW and LF) consumed 28 to $47 \mathrm{~kg}$ more than a group of seven genetic types (6 types of $\mathrm{F} 1$ and purebred MS), and about $70 \mathrm{~kg}$ more than purebred JX and JH sows.

In conclusion, these preliminary results seem to indicate that an appropriate cross between certain Chinese breeds (MS and JX) and an European breed (LW and LF) allows to use a F1 sow which has its first farrowing at least one month earlier, which is more economic (at least $100 \mathrm{~kg}$ of concentrate feed saved each year), and is more productive ( 5 to 7 more piglets weaned per year). As a consequence of that, the cost price of a weaned piglet can be reduced by 35 to 45 francs.

\title{
First results of experiments with chinese pigs in France \\ 2. Estimation of prolificacy factors : ovulation rate and foetal survival
}

\author{
P. ROMBAUTS *, G. MAZZARI **, F. DU MESNIL DU BUISSON * \\ *I.N.R.A., Station centrale de Physiologie animale, \\ F 78350 Jouy-en-Josas \\ ** Centre national de Recherches agronomiques, Maracay, Venezuela
}

To analyse the reasons for the prolificacy of Chinese breeds, Jia Xing (JX) and Mei Shan (MS), the ovulation rate of eleven 5-month old nulliparous sows was studied by coelioscopy for 5 successive cycles. The mean number of corpora lutea was 15.9 in the Jia Xing breed and 14.7 in the Mei Shan, i.e. it was comparable to Large White (LW) or French Landrace (LF) of about the same age.

The same observations were carried out for 4 cycles on $\mathrm{F}_{1}$-crossbred sows with a $\mathrm{Mei}$ Shan, Jia Xing or Jin Hua $(\mathrm{JH})$ father and a LW or LF mother. The effect of hybrid vigor was marked for this character in the JX-LF $(20.6 \pm 2.9$ ovulations) and JX-LW (16.7 $\pm 1,9$ ovulations).

These $F_{1}$ crosses (4 sows per group) were then slaughtered on day 50 of gestation to estimate the characteristics of gestation and calculate embryonic mortality. The percentage of embryonic survival and the number of live foetuses for the different groups were : 90.9 and 13.25 (JH-LF), 77.75 and 12.5 (JH-LW), 89.0 and 15.25 (MS-LF), 68.7 and 13.0 (MS-LW), 59.25 and 13.75 (JX-LF), 48.7 and 10.25 (JX-LW).

After day 50 of gestation, the number of foetuses in these sows was higher than in nulliparous Large White or Landrace sows. In the Mei Shan crosses, the large number of foetuses was associated with a particularly large uterine development. 